\title{
BENTUK DAN FUNGSI SAPAAN BAHASA PRANCIS DALAM NOVEL POIL DE CAROTTE KARYA JULES RENARD
}

\author{
Siti Perdi Rahayu \\ Universitas Negeri Yogyakarta \\ e-mail: perdi_rahayu@yahoo.fr
}

\begin{abstract}
Abstrak: Bentuk dan Fungsi Sapaan Bahasa Prancis dalam Novel Poil De Carotte Karya Jules Renard. Penelitian ini bertujuan untuk mendeskripsikan: 1) bentuk-bentuk sapaan dalam novel Poil de Carotte karya Jules Renard dan 2) fungsi kata-kata sapaan dalam novel tersebut. Sumber data dalam penelitian ini adalah semua kata, frasa, kalimat, dan ungkapan-ungkapan yang mengandung sapaan yang ada di dalam novel Poil de Carotte karya Jules Renard. Pengumpulan data menggunakan metode observasi. Analisis data menggunakan metode distribusional. Hasil penelitian menunjukkan bahwa: (1) bentuk sapaan yang ditemukan dalam novel Poil de Carotte karya Jules Renard berkategori: nomina: (a) nomina nama diri (nama depan, nama belakang, dan nama panggilan), (b) nomina umum (nom propre), pronomina, ajektiva, dan kombinasi, dan (2) fungsi sapaan dalam novel Poil de Carotte dapat diklasifikasikan menjadi 2, yaitu sebagai tanda masih adanya hubungan (fungsi fatik), dan sebagai alat pengontrol interaksi, ditandai dengan adanya interaksi antartokoh dalam melakukan tindak tutur untuk menyuruh, menolak, mengungkapkan perasaan, menegaskan, meminta kesediaan/meminta tolong/meminta sesuatu, menjawab, memohon, menyanggupi, merajuk, merayu, menyindir, meyakinkan, mengejek, dan mengkritik.
\end{abstract}

Kata kunci: bentuk sapaan, fungsi sapaan

\begin{abstract}
Form and Function of the French Terms of Address in The Novel "Poil de Carotte" by Jules Renard. This research aimed to describe: (1) the form of the French address terms in the novel Poil de Carotte by Jules Renard and (2) the function of the French address of terms in the novel. The data in this study were all words, phrases, sentences, and phrases containing the French terms of address, in the novel Poil de Carotte by Jules Renard. Data were collected by the observation method. Data were analysed using the distributional method. The results show that: (1) the novel Poil de Carotte of Jules Renard has a number of address terms. They are kindship address, noun: (a) noun proper name (first name, last name, and nickname), (b) the common noun, pronouns, adjective, and a combination of the previous forms, and (2) the address terms function in the novel Poil de Carotte can be classified into two, namely as a sign of the persistence of the relationship (function fatigue), occurs in speech acts to say hello, just a conversation, say congratulations, bid farewell, offered, reminding something, ask permission, jokingly, asked, and calling, then the second function is as a means of controlling the interaction, characterized by the interaction between the characters in speech acts to dismiss, refuse, express feelings, asserted, asked willingness, answer, and criticizing.
\end{abstract}

Keywords: form, function, terms of address in French 


\section{PENDAHULUAN}

Penggunaan

bentuk sapaan termasuk dalam kesantunan berbahasa dan etika berbahasa, yaitu bahwa bertindak laku berbahasa harus selalu disertai dengan norma-norma sosial dan sistem budaya yang berlaku dalam suatu masyarakat. Dalam masyarakat tersebut selalu terjadi interaksi antarindividu atau antarkelompok, dengan menggunakan bahasa, sehingga pada saat itulah akan terjadi tutur sapa, saling menyapa satu individu dengan individu lain, satu kelompok dengan kelompok lainnya. Untuk saling menyapa dalam interaksi sosial tersebut sering digunakan kata-kata sapaan, yang dapat menunjukkan seberapa dekat hubugan antarpenutur. Disamping itu kata sapaan juga dapat menyatakan kekuasaan dan kebersamaan. Hal ini sesuai dengan hubungan yang terjalin antara penutur dengan mitra tutur.

Sapaan termasuk dalam aspek kesantunan berbahasa, Setiap masyarakat mempunyai bentuk sapaan yang berbeda-beda, yang juga menunjukkan tingkat kesantunan yang berbeda-beda pula. Kesalahan dalam menyapa orang lain akan berakibat tidak baik dalam interaksi selanjutnya. Dengan demikian penggunaan sapaan ini haruslah menggambarkan sebuah kesantunan berbahasa. Menyapa menurut Nurhayati (2003) adalah salah satu kegiatan kontak sosial yang selalu dilakukan manusia dalam bermasyarakat, kegiatan menyapa dilakukan sesuai kaidah dan kebiasaan yang berlaku di masyarakatnya. Masyarakat Prancis juga mengenal adanya sapaan. Orang Prancis sangat terkenal sebagai orang yang formal, yang sangat menekankan sopan santun dan rasa hormat. Aturan sopan santun yang lain di Prancis adalah penggunaan pronomina $t u$ [ty] dan vous [vu]. Tu [ty] digunakan untuk menunjukkan keakraban, sedangkan vous [vu] digunakan untuk penggunaan lebih formal.

Selanjut Hart (2010) menguraikan tentang sikap umum yang dilihat dalam masyarakat Prancis setiap hari dan setiap tempat, yaitu berjabat tangan ketika bertemu dan berpamitan. Wanita boleh menawarkan pipinya kepada teman dekatnya untuk melakukan bise (bisous), ciuman (ciuman cepat di pipi) tergantung pada kedekatan mereka dan bahkan tergantung pada letak geografis tempat tinggalnya. Penduduk Paris biasanya hanya mencium sekali pipi kanan dan pipi kiri, sedangkan penduduk pedesaan mungkin akan mencium beberapa kali pada setiap pipi. Sedangkan untuk usia 20 tahun ke bawah aturan itu lebih mudah dan cepat. Bises dilakukan lebih bebas dan $t u$ 'kamu' merupakan sapaan yang lebih pantas.

Untuk menunjukkan adanya keanekaragaman penggunaan sapaan dalam berkomunikasi, khususnya masyarakat pengguna bahasa Prancis, perlu dilakukan penelitian tentang sapaan tersebut, Penelitian ini mengkhususkan penggunaan sapaan yang ada di dalam novel Poil de Carotte karya Jules Renard. Novel ini merupakan cerita otobigrafi, sehungga diharapkan semua tindak tutur yang ada dalam novel ini mirip atau mendekati kenyataan.

Penelitian tentang sapaan ini akan menggunakan teori sosiolinguistik, yaitu teori yang selalu memperhitungkan penggunaan bahasa dalam masyarakat, yang dipengaruhi oleh banyak faktor, antara lain: usia, jenis kelamin, status sosial, profesi, geografi, dan lain sebagainya. Kajian tentang sapaan ini termasuk dalam kajian sosiolinguistik mikro, yaitu kajian yang menelaah tentang siapa berbicara dalam (ragam) bahasa apa, kepada siapa, tentang apa atau siapa, dalam situasi 
apa, dengan maksud apa, dan sebagainya (Sumarsono, 2009).

Sapaan (address) adalah morfem, kata, atau frase yang dipergunakan untuk saling merujuk dalam situasi pembicaraan dan yang berbedabeda menurut sifat hubungan antara pembicara (Kridalaksana, 2008). Dalam bahasa Prancis istilah sapaan disebut apostrophe yaitu un mot sert à désigner la personne à qui s'adresse le locuteur (Riegel dkk, 2009). Apostrophe adalah kata yang digunakan untuk menggambarkan seseorang yang menjadi mitra tutur dari seorang pembicara (penutur). Berdasarkan bentuknya, kata sapaan dapat berbentuk: (1) Nama diri (nom propre) seperti: Leika, lâche ma manche! "Leika, lepaskan lengan bajuku!" (2) nomina (nom commun), misalnya: Garçon, une bière s'il vous plait! "Pelayan, tolong satu bir!", dan (3) pronomina persona (pronoms personnel), contoh: Toi, sors! "kamu, keluar!” (Riegel dkk, 2009). Nama dan gelar dalam sapaan merupakan faktor yang sangat penting dalam berbahasa, karena dapat menunjukkan posisi seseorang, karena dapat menunjukkan posisi sosial seseorang dalam hubungannya dengan orang lain di sekitarnya, sehingga nama dan gelar tersebut bisa menunjukkan status sosial seseorang (Evans-Pritchard, 1964). Sapaan disebut juga tutur sapa, yaitu pertuturan yang ditujukan kepada orang tertentu dengan kata tertentu yang bersangkutan dengan status dalam hubungan antara pembicara dengan orang tadi (Kridalaksana, 2008). Kata sapaan mempunyai bentuk yang mirip dengan kata acuan, tetapi kedua istilah itu sangat berbeda. Kata sapaan digunakan untuk menyapa seseorang yang diajak berbicara atau berkomunikasi, baik secara lisan maupun secara tertulis. Kata sapaan dapat berupa istilah kekerabatan, nama diri dan nama jabatan atau pangkat. Contoh: Bertrand, écoute-moi bien! Bertrand dalam kalimat tersebut merupakan kata sapaan yang berbentuk nama diri. Sedangkan kata acuan adalah kata yang digunakan untuk mengacu atau merujuk kepada orang yang dibicarakan. Kata acuan juga berkaitan dengan istilah kekerabatan, nama diri dan nama jabatan serta pangkat, contoh: Bertrand m'écoute bien. Bertrand dalam kalimat ini merupakan kata acuan yang berupa nama diri.

Menurut Wardhaugh (1986) dalam memilih bentuk sapaan, penutur dapat menggunakan gelar (title), nama depan (first name), nama belakang (last name), nama panggilan (nickname) atau gabungan antara bentuk-bentuk tersebut. Pemilihan bentuk-bentuk sapaan tersebut dipengaruhi oleh beberapa faktor, yaitu: kedewasaan sesorang, situasi status yang ditandai (status-marked situation), hubungan antarnonkerabat, pangkat (rank) dan seperangkat identitas (identity set), misal: gelar jabatan atau gelar kehormatan (Tripp, 1972). Dalam bahasa Prancis, kata dibedakan menjadi 9 kategori, yaitu: nomina, determinan, pronomina, ajektiva, verba, preposisi, adverbia, konjungsi, dan interjeksi (Bentolila, 2001).

Roman Jakobson (dalam Sudaryanto, 1990) menjelaskan bahwa fungsi bahasa ada enam, yaitu: (1) Fungsi emotif: Bahasa digunakan sebagai alat untuk mengungkapkan perasaan (ekspresi diri), (2) Fungsi konatif: Bahasa digunakan untuk memotivasi orang lain agar bersikap dan berbuat sesuatu. Bahasa sebagai pengungkap keinginan pembicara yang langsung atau segera dilakukan atau dipikirkan oleh sang penyimak, (3) Fungsi referensial: Bahasa yang digunakan sekelompok manusia untuk membicarakan suatu 
permasalahan dengan topik tertentu, (4) Fungsi puitik : Bahasa mengungkapkan pikiran, gagasan, perasaan kemauan dan tingkah laku seseorang, (5) Fungsi fatik: Bahasa digunakan untuk saling menyapa sekedar untuk mengadakan kontak, (6) Fungsi metalingual: Bahasa digunakan untuk membicarakan masalah bahasa dengan bahasa tertentu.

Menurut Jakobson (dalam Riegel $\mathrm{dkk}, 2009$ ) apostrophe atau sapaan mempunyai fungsi konatif apabila penutur menginginkan mitra tutur melakukan sesuatu, dan juga fungsi fatik apabila penutur sekedar ingin menunjukkan ada hubungan atau menjalin kontak dengan mitra tutur. Sedangkan menurut Kartomiharjo (1988) salam dan sapaan dapat memiliki dua fungsi, yaitu: (1) sebagai tanda bahwa kita memperhatikan orang yang kita sapa, suatu tanda masih adanya hubungan, bagaimanapun erat dan njauhnya antara penyapa dan yang disapa. Fungsi seperti ini oleh Brownislaw Malinowski (dalam Kartomiharjo, 1988) disebut sebagai phatic communication, dan (2) sebagai alat yang mengontrol interaksi. Di dalam berbagai masyarakat dapat dilihat bahwa orang yang memiliki status sosial lebih tinggi biasanya memiliki hak untuk mengontrol interaksi, dengan memilih sapaan sesuai dengan ragam yang dikehendaki, sedangkan orang yang berstatus sosial lebih rendah mengikuti kehendaknya

Pemakaian bahasa pada dimensi sosial budaya komunikasi masyarakat tutur, termasuk penggunaan bentuk sapaan sangat dipengaruhi oleh komponen tutur. Menurut Hymes (dalam Sumarsono, 2009), ada 16 komponen tutur yang yang dirangkum menjadi delapan komponen tutur dalam sebuah akronim bahasa Inggris yang bermakna WICARA, yaitu SPEAKING atau dalam bahasa Prancis PARLANT.
SPEAKING merupakan singkatan dari S (Setting dan Scene), Setting atau latar yaitu mencakup waktu dan tempat terjadinya tindak tutur, biasanya mengacu pada keadaan fisik, Scene atau suasana mengacu kepada latar psikologis, atau batasan budaya tentang suatu kejadian sebagai suatu jenis suasana tertentu. Misalnya: formal menjadi informal, serius menjadi santai, dan sebagainya. $\mathrm{P}$ (Partisipant), yaitu orang-orang yang terlibat dalam petuturan, yang meliputi penutur, mitra tutur atau pengirim dan penerima, pendengar. Sedangkan E (End) atau tujuan, yaitu mencakup maksud dan hasil, A (Act sequence) atau urutan tindak mencakup (1) bentuk pesan, yaitu cara bagaimana suatu topik dikatakan atau diberitakan, dan (2) isi pesan, yaitu berkaitan dengan persoalan apa yang dikatakan, menyangkut topik dan perubahan topic. K (Key) atau kunci, yaitu mengacu kepada cara, nada, atau jiwa (semangat) tindak tutur dilakukan, dalam kategori gramatikal kunci ini sejajar dengan modalitas, misalnya: serius, santai, hormat, tak hormat, sederhana, angkuh, yakin tak yakin, dan sebagainya.

Adapaun unsur I (Instrumentalities) atau peranti/perabotan, yaitu mencakup saluran dan bentuk tutur. saluran mengacu pada medium penyampaian: lisan, tertulis, telegram, telepon, dan sebagainya. Bentuk tutur mengacu pada tatanan perabot kebahasaan yang berskala bahasa, dialek, misalnya: ragam bahasa, register, dan sebagainya. Unsur $\mathrm{N}$ (Norms) atau norma, mencakup norma interaksi dan norma interpretasi. Norma interaksi adalah perilaku khas dan sopan santun tutur yang mengikat dalam suatu pertuturan, misalnya : boleh menyela atau tidak boleh menyela, dan sebagainya, sedangkan norma interpretasi adalah merupakan interpretasi dari interaksi sesuai dengan budaya yang ada. Unsur 
G (Genre) atau tipe atau kategori tuturan yang digunakan, misalnya : puisi, mite, dongeng, peribahasa, teka-teki, doa, cacian, edaran, dan sebagainya.

Penelitian ini mengungkapkan berbagai bentuk sapaan yang digunakan dalam novel Poil de Carotte karya Jules Renard, dan fungsi penggunaan sapaan tersebut. Penggunaan sapaan ini juga dapat menunjukkan adanya hubungan yang saling mempengaruhi antara bahasa dan masyarakat.

\section{METODE}

Objek penelitian adalah semua kata dan frasa yang merupakan sapaan. Adapun data dalam penelitian ini adalah semua kata, frasa, kalimat, dan ungkapan-ungkapan yang mengandung sapaan. Sumber data adalah novel Poil de Carotte karya Jules Renard. Novel ini merupakan roman otobiografi.

Pada tahap pengumpulan data, digunakan metode simak, yaitu metode yang dilakukan dengan cara menyimak penggunaan bahasa (Sudaryanto, 1993 dan Kesuma, 2007) dengan teknik dasar teknik sadap dilanjutkan dengan teknik lanjutan SBLC (Simak Bebas Libat Cakap) dan teknik catat, yaitu mencatat semua data pada komputer. Setelah data terkumpul kemudian diklasi-fikasikan berdasarkan: (1) bentuk Sapaan dan (2) fungsi sapaan.

Untuk menganalisis data digunakan metode agih dan metode padan. Menurut Sudaryanto (1993) dan Kesuma (2007) metode agih adalah metode analisis bahasa yang alat penentunya adalah bagian dari bahasa yang bersangkutan itu sendiri. Sedangkan metode padan adalah metode analisis bahasa yang alat penentunya ada di luar, terlepas, dan tidak menjadi bagian dari bahasa (langue) yang bersangkutan (Kesuma, 2007). Metode agih ini akan digunakan untuk menentukan bentuk-bentuk sapaan yang digunakan dalam novel Poil de Carotte, teknik yang digunakan adalah teknik dasar, yaitu teknik bagi unsur langsung (teknik BUL) dan teknik lanjutan, yang berupa teknik baca markah, teknik perluas, maupun teknik ganti. Penggunaan berbagai teknik analisis ini disesuaikan dengan karakter data. Teknik BUL adalah teknik yang dilakukan dengan cara membagi data menjadi beberapa satuan lingual (konstiuen) (Sudaryanto, 1993; Baryadi, 2000; Kesuma, 2007). Teknik baca markah adalah teknik analisis dengan melihat langsung pemarkah yang ada dalam suatu konstruksi (Sudaryanto, 1993; Kesuma, 2007). Pemarkah atau penanda adalah alat seperti afiks, konjungsi, preposisi, dan artikel yang menyatakan ciri gramatikal atau fungsi kata atau konstruksi (Kridalaksana, 2008).

Adapun untuk mengetahui fungsi penggunaan sapaan digunakan metode analisis kontekstual, yaitu metode analisis yang mendasarkan dan mengaitkan dengan konteks (Rahardi, 2009: 36). Metode analisis kontekstual ini sejajar dengan metode padan yang disampaikan oleh Sudaryanto (1993) dan Mahsun (2005), yaitu memadankan bentukbentuk sapaan dengan segala sesuatu yang sifatnya luar kebahasaan atau ekstralingual. Teknik dasar yang dipakai adalah teknik hubung banding yang bersifat ekstralingual dan diikuti dengan teknik lanjutan yang berupa teknik hubung banding menyamakan dan teknik hubung banding membedakan, serta teknik hubung banding menyamakan hal pokok.

Uji validitas data yang digunakan adalah validitas semantis, yaitu mengukur tingkat kesensitifan suatu teknik terhadap makna-makna simbolik yang 
relevan dengan konteks tertentu. Makna semantis dapat dicapai apabila maknamakna tersebut berhubungan dengan penerima pesan, sumber pesan, isi pesan, dan konteks lainnya dari data-data yang dianalisis (Darmiyati, 1993). Sedangkan uji reliabilitas adalah stabilitas yang didukung expertjudgement, yaitu peneliti membaca berulang-ulang kata, frasa, dan kalimat yang ada dalam sumber data, dan apabila terdapat keraguan, peneliti berdiskusi dengan sesama dosen yang serumpun bidang ilmu atau dengan dosen senior atau ahli yang lebih menguasai bidang tersebut (Darmiyati, 1993).

\section{HASIL DAN PEMBAHASAN}

Penelitian ini menemukan 87 data, kemudian dianalisis dan ditemukan adanya bentuk-bentuk sapaan yang dapat diklasifikasikan menjadi beberapa, yaitu: nomina (nomina nama diri, nomina umum), pronomina, ajektiva, dan kombinasi dari bentuk-bentuk yang sebelumnya. Berdasarkan fungsinya, bentuk sapaan dalam roman Poil de Carotte dapat diklasifikasikan menjadi dua, yaitu sebagai tanda masih adanya hubungan (fungsi fatik) dan sebagai alat pengontrol interaksi. Berikut ini akan diuraikan bentuk-bentuk sapaan dan fungsi sapaan tersebut.

\section{Bentuk Sapaan}

Bentuk sapaan yang ada dalam roman Poil de Carotte dibedakan menjadi nomina (nomina nama diri, nomina umum), pronomina, ajektiva, dan kombinasi dari bentuk-bentuk yang sebelumnya.

\section{Nomina Nama Diri (Nom Propre) \\ Nama Depan}

(1) Je parie, dit Mme Lepic, qu'Honorine a encore oublié de fermer les poules. C'est vrai. On peut s'en assurer par la fenêtre. Là-bas, tout au fond de la grande cour, le petit toit aux poules découpe, dans la nuit, le carré noir de sa porte ouverte.

Félix, si tu allais les fermer dit Mme Lepic à l'aîné de ses trois enfants.

Je ne suis pas ici pour m'occuper des poules, dit Félix, garçon pâle, indolent et poltron.

(Poil de Carotte, Jules RENARD p.1)

"Aku yakin kalau Honorine lupa lagi menutup kandang ayam," kata Bu Lepic. Hal tersbut memang benar. Dari kejauhan tampak ayam-ayam berkeliaran di halaman luas karena pintu kandangnya terbuka pada malam hari.

"Félix, bersediakah kamu menutupnya?" Tanya $\mathrm{Bu}$ Lepic kepada putranya yang paling sulung dari tiga bersaudara.

"Aku berada di sini bukan untuk mengurusi ayam," jawab Félix, anak laki-laki berkulit pucat, pemalas, dan penakut.

Kata Félix pada contoh (1) di atas merupakan sapaan, yaitu sapaan dari seorang ibu (Madame Lepic) kepada anak sulungnya yang bernama Felix. Pada petang hari Madame Lepic meminta tolongFelixuntukmenutupkandangayam, karena Honorine (pembantunya) lupa melakukannya. Percakapan ini dilakukan dengan menggunakan bahasa lisan secara tegas dan lembut. Berdasarkan kategori leksikalnya, sapaan Felix berbentuk nomina, yaitu nomina nama diri, karena diawali dengan huruf capital. Dikatakan berkategori nomina, karena kata tersebut bisa menduduki fungsi subjek, objek, atau atribut dalam sebuah kalimat, perhatikan contoh berikut.

(1a) Félix ne veut pas fermer la porte $\mathrm{S} \quad \mathrm{P} \quad \mathrm{O}$ 
(1b) Madame Lepix ordonne à Félix $\mathrm{S} \quad \mathrm{P} \quad \mathrm{O}$

de fermer la porte

$\mathrm{K}$

(1c) Le grand frère de Poil de Carotte est $\mathrm{S}$ $\mathrm{P}$

Félix

Atribut

Kata Félix pada contoh (1a), (1b), dan (1c) membuktikan bahwa kata tersebut berkategori nomina. Contoh (1a) mendudukkan kata Félix sebagai subjek kalimat, contoh (1b) mendudukan kata Felix pada fungsi objek (0), sedangkan pada contoh (1c) kata Félix berfungsi sebagai atribut.

Kata sapaan Félix merupakan nomina nama diri, karena ditulis dengan awal huruf kapital, dan juga merupakan nama depan, karena Félix mempunyai nama lengkap Félix Lepic. Lepic adalah nama keluarga.

Nama Belakang

(2) Mme Lepic en train de se bavarde avec Honorine.

MADAME LEPIC: Quel âge avez-vous donc, déjà, Honorine?

HONORINE: Soixante-sept ans depuis la Toussaint, madame Lepic.

MADAME LEPIC: Vous voilà vieille, ma pauvre vieille!

HONORINE: Ça ne prouve rien, quand on peut travailler. Jamaisje n'ai été malade. Je crois les chevaux moins durs que moi.

(Poil de Carotte, Jules RENARD p.23)

$\mathrm{Bu}$ Lepic sedang berbincang-bincang dengan Honorine.

$\mathrm{Bu}$ Lepic: "Usiamu sudah berapa, Honorine?"

Honorine: "Enam puluh tujuh sejak Hari Toussaint, $\underline{B u}$ Lepic.
Bu Lepic: "Sudah setua itu kah, si tua malangku!"

Honorine: "Itu tidak membuktikan apapun ketika kita bekerja. Aku tidak pernah sakit. Aku percaya kuda-kuda tidak lebih kuat dibanding diriku".

Kata Madame Lepic pada contoh (2) di atas merupakan sapaan, yaitu sapaan yang digunakan seorang pembantu rumah tangga, Honorine, kepada majikan perempuannya, Madame Lepic. Percakapan ini dilakukan ketika keduanya sedang duduk-duduk di rumah keluarga Lepic. Madame Lepic menanyakan berapa usia Honorine, si pembantu tersebut, dan pembantu itupun menjawab dengan penuh sopan santun sambil menyebutkan nama tuannya, Madame Lepic. Sapaan Madame Lepic ini memiliki kategori leksikal sebagai nomina, yaitu nomina nama diri, karena diawali dengan huruf kapital. Dikatakan berkategori nomina, karena kata tersebut bisa menduduki fungsi subjek, objek, atau atribut dalam sebuah kalimat, perhatikan contoh berikut.

(2a) Madame Lepic n'aime pas le cadet $\begin{array}{lll}\mathrm{S} & \mathrm{P} & \mathrm{O}\end{array}$

(2b) M. Lepic parle à Madame Lepic $\mathrm{S} \quad \mathrm{P} \quad \mathrm{O}$

(2c) La mère de Poil de Carotte est

$\mathrm{S}$
$\frac{\text { adame Lepic }}{\text { Atribut }}$

Kata Madame Lepic pada contoh (2a), (2b), dan (2c) membuktikan bahwa kata tersebut berkategori nomina. Contoh (2a) mendudukkan kata Madame Lepic sebagai subjek kalimat, contoh (2b) mendudukan kata Madame Lepic pada fungsi objek (0), sedangkan pada contoh (2c) kata Madame Lepic berfungsi sebagai atribut. 
Kata sapaan (Madame) Lepic merupakan nomina nama diri, karena ditulis dengan awal huruf kapital, dan juga merupakan nama depan, karena Lepic adalah nama keluarga. Sedangkan nama depan dari madame Lepic tidak disebutkan.

Nama Panggilan

(3) MONSIEUR LEPIC: Poil de Carotte tu n'as pas travaillé l'année dernière comme j'espérais. Tes bulletins disent que tu pourrais beaucoup mieux faire. POIL DE CAROTTE: Compte sur moi, papa. Je t'accorde que je me suis un peu laissé aller l'année dernière.

(Poil de Carotte, Julest RENARD p.44)

Pak Lepic: "Rambut Wortel, tahun lalu kau tidak bekerja sesuai harapanku. Catatanmu mengatakan kau bisa melakukannya lebih baik". Rambut Wortel: "Percayalah padaku, ayah. Aku berjanji tidak mengulangi tahun sebelumnya".

Poil de Carotte dalam contoh (3) merupakan sapaan, yaitu sapaan yang disampaikan oleh seorang bapak Monsieur Lepic kepada anaknya yang bernama François Lepic, tetapi sehariharinya dipanggil Poil de Carotte, karena warna rambutnya pirang atau rambut jagung. Percakapan ini dilakukan di rumah keluarga Lepic pada saat Monsieur Lepic melihat catatan hasil belajar milik Poil de Carotte dan ia berkesimpulan bahwa putranya itu tidak belajar sesuai harapannya. Meski demikian Monsieur Lepic tidak marah kepada anaknya, bahkan Monsieur Lepic tetap dengan sabar mengelus putranya itu.

Sapaan Poil de Carotte ini berkategori nomina, yaitu nomina nama diri yang berupa nama panggilan, karena penulisannya diawali dengan huruf kapital. Kata Poil de Carotte yang berkategori nomina tersebut dapat dibuktikan dengan mendudukkan kata tersebut dalam fungsi subjek, objek atau atribut. Perhatikan contoh berikut.

3a) Poil de Carotte est

$\mathrm{S} \quad \mathrm{P}$

une œuvre de Jules Renard publiée en 1894 atribut

(3b) Madame Lepic déteste Poil de Carrote $\mathrm{S} \quad \mathrm{P} \quad \mathrm{O}$

(3c) Le fils cadet de M et Mme Lepic est $\mathrm{S}$ $\mathrm{P}$

\section{Poil de Carotte atribut}

Bentuk sapaan Poil de Carotte nomina, karena bentu tersebut dapat menduduki fungsi subjek (S) dalam sebuah kalimat, seperti yang terlihat pada kalimat (3a), juga dapat menempati fungsi objek (O) kalimat, seperti yang tertera pada contoh kalimat (3b), dan dapat juga berfungsi sebagai atribut dalam suatu kalimat, seperti yag terlihat pada kalimat (3c).

Poil de Carotte merupakan nama panggilan, karena nama sebenarnya adalah François Lepic. Dipanggil Poil de Carotte karena François Lepic memiliki rambut yang berwarna pirang dan bintikbintik coklat di mukanya.

\section{Nomina Umum (Nom Commun)}

(4) Monsieur Lepic, Félix, et Poil de Carotte chassent. M. Lepic donne une carabine pour ses fils.

MONSIEUR LEPIC: Allez, mes enfants, amusez-vous sans vous disputer.

(Poil de Carotte, Jules RENARD p.11)

Pak Lepic, Félix, dan Rambut Wortel pergi berburu. Pak Lepic memberikan sebuah senapan untuk putra-putranya. Pak Lepic: "Ayo anak-anakku, bersenang-senanglah tanpa berebut". 
Satuan lingual mes enfants "anakanakku" pada contoh (4) merupakan bentuk sapaan, yaitu sapaan yang digunakan seorang bapak, Monsieur Lepic, kepada anak-anaknya, Felix dan Poil de Carotte. Penggunaan sapaan ini dilakukan ketika mereka berada di hutan, saat berburu. Monsieur Lepic menyuruh anak-anaknya tidak berebut karena ia hanya memberikan satu senapan, meski kedua anaknya saling berebut, tapi Monsieur Lepic melerainya dengan penuh kesabaran dan tegas. Berdasarkan kategori leksikalnya, sapaan mes enfant ini berkategori nomina, yaitu nomina umum (nom commun). Kategori nomina pada bentuk sapaan tersebut dapat dibuktikan dengan menempatkan kata mes enfants tersebut pada kalimatkalimat berikut.

(4a) Mes enfants $\underline{\text { s'amusent }}$ sans se $\mathrm{S} \quad \mathrm{P}$ disputer $\mathrm{K}$

(4b) J'aime bien mes enfants $\mathrm{S} \quad \mathrm{P} \quad \mathrm{K}$

(4c) Ceux que j'aime bien sont mes enfants $\mathrm{S} \quad \mathrm{P}$ Atribut

Satuan mes enfants pada kalimat (4a) menduduki fungsi sebagi subjek (S) kalimat, sedangkan pada kalimat (4b) nomina mes enfants menempati fungsi objek (0), dan pada kalimat (4c) nomina mes enfants tersebut berfungsi sebagai atribut. Hal ini membuktikan bahwa satuan mes enfants betul-betul berkategori nomina.

\section{Pronomina}

(5) Félix et Poil de Carotte arrivent chez eux. - Je crois que nos parents n'y sont pas. Frappe du pied, toi, dit-Il. (Poil de Carotte, Jules RENARD p.13)
Félix dan Rambut Wortel sampai di rumah mereka.

"Aku yakin orang tua kita tidak di rumah. Kau, gebrak pintunya!" Perintah Félix.

Toi "kamu" pada contoh (5) merupakan bentuk sapaan, yaitu sapaan yang digunakan seorang kakak, Felix, kepada adiknya Poil de Carotte. Percakapan ini terjadi di depan pintu rumah keluarga Lepic, saat mereka pulang dari berburu. Felix sang kakak dengan nada agak kesal menyuruh adiknya, Poil de Carotte mendobrak pintu rumah dengan kaki, karena orang tua mereka tidak segera membukakan pintu, dan ternyata orang tua mereka tidak ada di rumah.

Berdasarkan kategori leksikalnya, sapaan Toi "kamu" memiliki berkategori pronomina, yaitu kata yang menggantikan kata lain yang berada pada kalimat sebelumnya. Berdasarkan konteks yang ada kata toi mengacu pada Poil de Carotte yang ada pada kalimat sebelumnya. Hal tersebut dapat dibuktikan dengan menempatkan nomina acuannya, Poil de Carotte, pada pronomina toi:

(5a) Félix et Poil de Carotte arrivent chez eux. - Je crois que nos parents n'y sont pas. Frappe du pied, Poil de Carotte, dit-Il (Félix).

Ternyata dengan mengembalikan nomina acuannya Poil de Carotte pada tempat pronomina, secara gramatikal dapat diterima dan makna kalimat itu tidak berubah, sehingga dapat dikatakan bahwa pronomina toi mengacu pada Poil de Carotte.

\section{Ajektiva}

(6) Mme Lepic demande Poil de Carotte pour lui aider.

MADAME LEPIC: Ici, mignon, aidemoi. Réfléchissons. On ne saurait 
soupçonner ton père de négligence, à son âge. Ta soeur met ses économies dans sa tirelire. Ton frère n'a pas le temps de perdre son argent, un sou fond entre ses doigts. Après tout, c'est peut-être moi.

POIL DE CAROTTE: Maman, cela m'étonnerait; tu ranges si soigneusement tes affaires.

(Poil de Carotte, Julest RENARD p.73)

$\mathrm{Bu}$ Lepic mengajak Rambut Wortel untuk membantunya.

Bu Lepic: "Kemari, sayang, tolong aku. Mari kita merenung. Tidak banyak yang tahu kalau ayahmu ceroboh saat seusiamu. Saudarimu menempatkan uangnya dalam celengan. Kakak lakilakimu tidak pernah mengambil uangnya, seperduapuluh sen dalam genggaman jarinya. Semua itu, mungkin aku.

Rambut Wortel: "Ibu, itu mengagetkanku, kau menyusun semua urusanmu dengan teliti.

Satuan lingual mignon "saying" pada contoh (6) merupakan bentuk sapaan, yaitu sapaan yang digunakan oleh sorang ibu, Madame Lepic kepada anaknya Poil de Carotte. Percakapan antara ibu dan anak ini terjadi di rumah. Madame Lepic memanggil anaknya, Poil de Carotte untuk segera datang dan duduk bersamanya, kemudian diajak berdiskusi.

Berdasarkan kategori leksikalnya, sapaan mignon "sayang" memiliki kategori ajektiva. Hal ini dapat dibuktikan dengan menempatkan ajektiva mignon sebagai épithète dan sebagai atribut, sebagaimana fungsi ajektiva. Perhatikan contoh (6a) dan (6b) berikut.

(6a) Un bébé mignon est en train de pleurer $\mathrm{S}$ $\mathrm{P}$

(6b) La jeune petite fille est mignonne

$$
\mathrm{S} \quad \mathrm{P} \text { atribut }
$$

Kata mignon pada kalimat (6a) merupakan ajektiva yang berfungsi sebagai épithète, karena ajektiva tersebut menempel langsung dan memberi kualitas pada nomina un bébé. Sedangkan ajektiva mignonne pada kalimat (6b) berfungsi sebagai atribut, yang memberi kualitas atau keterangan pada nomina $l a$ jeune petite fille. Karena bisa berfungsi sebagai épithète dan atribut, maka satuan mignon(ne) termasuk kata yang berkategori ajektiva.

\section{Kombinasi}

(7) MADAME LEPIC: Mon petit Poil de Carotte chéri, je t'en prie, tu serais bien mignon d'aller me chercher une livre de beurre au moulin. Cours vite. On t'attendra pour se mettre à table. POIL DE CAROTTE: Non, maman.

(Poil de Carotte, Julest RENARD p.81)

\section{$\mathrm{Bu}$ Lepic: "Sayangku Rambut}

Wortel, aku memohon padamu, kau akan semakin lucu jika pergi mencarikanku setengah kilogram mentega kocok. Cepatlah. Kami menunggu untuk meletakkannya di meja."

Rambut Wortel : "tidak, ibu."

Mon petit Poil de Carotte chéri "Sayangku Rambut Wortel" pada contoh (7) merupakan sapaan, yaitu sapaan yang digunakan seorang ibu, Madame Lepic, kepada anak bungsunya Poil de Carotte. Peristiwa tutur ini terjadi di rumah keluarga Lepic. Ibu menyuruh anaknya untuk mencarikan atau membelikan mentega kocok, tetapi anaknya, Poil de Carotte tidak mau. Bentuk sapaan ini tersusun dari kombinasi antara ajektiva, dan nomina nama diri kategori nama panggilan plus ajektiva. Secara keseluruhan Mon petit Poil de Carotte chéri berkategori nomina. Sebagai 
nomina seharusnya bentuk sapaan itu bisa menduduki fungsi subjek, objek maupun atribut dalam sebuah kalimat. Perhatikan contoh berikut.

(7a) LepetitPoil de Carotte chéri ne cherchepas $\mathrm{S}$ $\mathrm{P}$ de beurre au moulin

0

(7b) Madame Lepic appelle

$\mathrm{S} \quad \mathrm{P}$

le petit Poil de Carotte chéri

0

(7c) Le cadet de Met Mme Lepic est $\mathrm{S} \quad \mathrm{P}$

le petit Poil de Carotte chéri atribut

Le petit Poil de Carotte chéri pada kalimat (7a) dapat menduduki fungsi sintaksis sebagai subjek (S), sedangkan pada kalimat (7b) Le petit Poil de Carotte chéri menempati fungsi sintaksis dalam kalimat sebagai objek (0). Pada kalimat (7c) Le petit Poil de Carotte chéri berfungsi sebagai atribut.

\section{Fungsi Sapaan}

Sebagai Tanda Masih Adanya Hubungan (Fungsi Fatik)

Sapaan yang berfungsi sebagai tanda adanya hubungan (fungsi fatik) dalam novel Poil de Carotte ini ditandai dengan adanya interaksi antar tokoh dalam melakuakn tindak tutur untuk menyapa, sekedar bercakap-cakap, mengucapkan selamat, menyampaikan salam perpisahan, menawarkan diri, mengingatkan sesuatu, meminta ijin, bergurau, bertanya, dan memanggil. Contoh:

(8) Poil de Carotte tombe dans un eau.

- Tu plonges bien, mon garçon, lui dit M. Lepic.

- Oui, dit Poil de Carotte, quoique je n'aime pas beaucoup ça. L'eau reste dans mes oreilles, et j'aurai mal à la tête.

(Poil de Carotte, Jules RENARD p.23)

Rambut Wortel jatuh ke dalam sebuah perairan.

"Kau terjun dengan baik, anakku," kata Pak Lepic padanya.

"Ya, meskipun aku sangat tidak menyukainya. Air masuk dalam telingaku dan aku akan sakit kepala," jata Rambut Wortel.

Konteks contoh (8) dapat diuraikan sesuai dengan komponen tutur yang menyertainya, yaitu yang tergabung dalam akronim SPEAKING: S(Setting and scene) dalam tuturan (8) adalah di sungai, $\mathrm{P}$ (Participant) adalah M. Lepic dan Poil de Carotte, E (End) mengejek, A (Act) M Lepic mengejek Poil de Carotte yang terjatuh ke sungai, K (Key) datar, I (instrument) menggunakan bahasa lisan, N (Norms) norma kesopanan, dan G (genre) tuturan yang digunakan berbentuk percakapan.

Berdasarkan konteks yang berupa komponen tutur di atas bentuk sapaan Mon Garçon pada contoh (8) berfungsi fatik yaitu sapaan mon garçon digunakan oleh M. Lepic untuk menyapa Poil de Carotte dengan mengejeknya, karena Poil de Carotte terjatuh ke sungai.

\section{Sebagai Alat Pengontrol Interaksi}

Sapaan yang berfungsi sebagai alat pengontrol interaksi dalam novel Poil de Carotte ini ditandai dengan adanya interaksi antartokoh dalam melakukan tindak tutur untuk menyuruh, menolak, mengungkapkan perasaan, menyanggah, menegaskan dan lain-lain. Contoh:

(9) Félix et Ernestine refusent de fermer les poules.

- Dieu, que je suis bête! dit Mme Lepic. Je n'y pensais plus. Poil de Carotte, va 
fermer les poules! Elle donne ce petit nom d'amour à son dernier-né, parce qu'il a les cheveux roux et la peau tachée!

Poil de Carotte, qui joue à rien sous la table, se dresse et dit avec timidité:

- Mais, maman, j'ai peur aussi, moi. (Poil de Carotte, Jules RENARD p.1)

Félix dan Ernestine menolak menutup kandang ayam.

"Tuhan, bodohnya aku! Aku tidak habis pikir. Rambut Wortel, pergi tutup kandang ayam!" Bu Lepic memangil putra bungsu kesayangannya demikan karena rambutnya berwarna merah serta kulitnya berbintik. Rambut Wortel yang sedang bermain di bawah meja berdiri dan berkata dengan malumalu: "tapi Bu, aku juga takut."

Konteks contoh (9) dapat diuraikan sesuai dengan komponen tutur yang menyertainya, yaitu yang tergabung dalam akronim SPEAKING, S dalam tuturan (9) adalah di rumah keluarga Lepic pada petang hari, P (Participant) adalah mme Lepic dan Poil de Carotte, E (End) menyuruh, A (Act) mme Lepic menyuruh Poil de Carotte untuk segera menutup kandang ayam karena Felix dan Ernestine tidak bersedia melakukannya, $\mathrm{K}$ (Key) tegas dan terkesan marah, I (instrument) menggunakan bahasa lisan, $\mathrm{N}$ (Norms) norma kesopanan, dan G (genre) tuturan yang digunakan berbentuk percakapan.

Berdasarkan konteks yang berupa komponen tutur di atas bentuk sapaan Poil de Carotte pada contoh (9) berfungsi konatif yaitu bahwa sapaan yang diucapkan oleh Mme Lepic tersebut digunakan untuk memotivasi anaknya, Poil de Carotte, agar mau menutup pintu kandang ayam, karena kedua kakaknya tidak bersedia menutup. Tetapi Poil de Carotte juga menolak untuk menutup, karena dia juga takut seperti kakaknya.

\section{SIMPULAN}

Setelah melakukan rangkaian proses penelitian, yaitu pengumpulan data, klasifikasi data, dan analisis data, maka peneliti dapat menyimpulkan hal-hal yang ditemukan sesuai dengan tujuan awal dari penlitian ini. Kesimpulan penelitian ini meliputi: (1) Bentuk-bentuk sapaan yang ditemukan dalam roman Poil de Carotte karya Jules Renard berupa satuansatuan yang berkategori: nomina, yang dibedakan menjadi nomina nama diri (nama depan, nama belakang, dan nama panggilan), nomina umum (nom propre), pronomina, ajektiva, dan kombinasi dari bentuk-bentuk sebelumnya, dan (2) Berdasarkan fungsinya, bentuk sapaan dalam roman Poil de Carotte dapat diklasifikasikan menjadi 2, yaitu sebagai tanda masih adanya hubungan (fungsi fatik) dan sebagai alat pengontrol interaksi. Sapaan yang berfungsi sebagai tanda adanya hubungan (fungsi fatik) dalam novel Poil de Carotte ini ditandai dengan adanya interaksi antar tokoh dalam melakukan tindak tutur untuk menyapa, sekedar bercakap-cakap, mengucapkan selamat, menyampaikan salam perpisahan, menawarkan diri, mengingatkan sesuatu, meminta ijin, bergurau, bertanya, dan memanggil. Sedangkan sapaan yang berfungsi sebagai alat pengontrol interaksi dalam novel Poil de Carotte ini ditandai dengan adanya interaksi antartokoh dalam melakukan tindak tutur untuk menyuruh, menolak, mengungkapkan perasaan, menyanggah, menegaskan, dan lain-lain

\section{Ucapan Terima Kasih}

Artikel ini disarikan dari hasil penelitian mandiri yang dilaksanakan di 
Fakultas Bahasa dan Seni pada tahun 2013 dengan anggaran dana DIPA UNY tahun 2013 alokasi FBS. Ucapan terrima kasih kami sampaikan kepada DPP Penelitian FBS UNY, khususnya bidang bahasa, yang telah memfasilitasi penelitian ini hingga selesai. Ucapan terima kasih juga kami sampaikan kepada Mugi Artiningsih, S.Pd dan Rachma Wulan Maulida mahasiswa Jurusan Pendidikan Bahasa Prancis yang telah membantu pelaksanaan penelitian ini, dan juga kepada reviewer yang telah mengoreksi dan memberi masukan terhadap artikel ini.

\section{Daftar Pustaka}

Baryadi, I.P. 2000. Konstruksi Perurutan Waktu pada Tataran Kalimat dalam Wacana Bahasa Indonesia. Disertasi. Yogyakarta: Fakultas Ilmu Budaya UGM.

Bentolila, A. 2001. Grammaire Alphaetique. Paris: Nathan.

Zuchdi, D. 1993. Panduan Penelitian Analisis Konten. Yogyakarta: Lemlit IKIP Yogyakarta.

Ervins-Tripp, S.M. 1972. Sociolinguistcs Rules of Address dalam J.B. Pride and Janet Holmes (ed.). Sociolinguistics Selected Reading. Middlesex: Penguin Books.

Evans-Pritchard, E.E. 1964. Nuer Modes of Address dalam Dell Hymes (ed.) Language in culture and Socie-ty: A Reader in Linguistics and Antroppology. New York: Haper and Row.

Hart, A. 2010. Tinggal dan Bekerja di Prancis. Yogyakarta: PT. Bentang Pustaka.
Kartomihardjo, S. 1988. Bahasa Cermin Kehidupan Masyarakat. Jakarta: Departemen Pendidikan dan Kebudayaan, Direktorat Jendral Pendidikan, Proyek Pengembangan Lembaga Pendidikan Tenaga Kependidikan, Jakarta.

Kesuma, T.M.J. 2007. Pengantar (Metode) Penelitian Bahasa. Yogyakarta: Caras-watibooks.

Kridalaksana, H. 2008. Kamus Linguistik. Jakarta: PT Gramedia Pustaka Utama

Mahsun, M.S, 2005. Metode Penelitian Bahasa: Tahapan, Strategi, Metode dan Tekniknya. Jakarta: Rajawali Pers.

Nurhayati, E. 2003. Sistem Sapaan dalam Pertunjukan Wayang Kulit. Laporan Penelitian. FBS UNY.

Riegel, deM, Pellat, J.C., Rioull, R. 2009. Grammaire Méthodique du Français. Paris: Presses Universitaires de France.

Sudaryanto. 1990. Menguak Fungsi Hakiki Bahasa. Yogyakarta: Duta Wacana University Press.

Sudaryanto. 1993. Metode dan Aneka Teknik Analisis Bahasa: Pengantar Penelitian Wahana Kebudayaan secara Linguistis. Yogyakarta: Duta Wacana University Press.

Sumarsono, 2009. Sosiolinguistik. Yogyakarta: SABDA (Lembaga Studi Agama, Budaya, dan Perdamaian) dan Pustaka Pelajar.

Wardhaugh. R. 1980. Introduction to Sociolinguistics. Oxford: Basil Blackwell. 